Research Article

\title{
Integrated Inventory-Transportation Scheduling with Sustainability-Dependent Demand under Carbon Emission Policies
}

\author{
Zhongming Tang, ${ }^{1}$ Xingxing Liu, ${ }^{2}$ Ying Wang, ${ }^{1}$ and Da Ma ${ }^{1}{ }^{1}$ \\ ${ }^{1}$ School of Management, Hubei University of Education, Wuhan 430205, China \\ ${ }^{2}$ School of Safety Science and Emergency Management, Wuhan University of Technology, Wuhan 430070, China \\ Correspondence should be addressed to Da Ma; mada0618@163.com
}

Received 14 July 2020; Revised 20 August 2020; Accepted 31 August 2020; Published 26 September 2020

Academic Editor: Chin-Chia Wu

Copyright (c) 2020 Zhongming Tang et al. This is an open access article distributed under the Creative Commons Attribution License, which permits unrestricted use, distribution, and reproduction in any medium, provided the original work is properly cited.

Carbon policies and consumer environmental consciousness are effective motivators that drive enterprises to adopt sustainability technology. To provide enterprises insights into sustainable investment and inventory-transportation decision-making and governments insights into policy-making, this study investigates integrated inventory-transportation scheduling considering consumer environmental consciousness and sustainability technology under carbon cap, tax, and cap-and-trade policies. We first examined sustainability that extends the economic order quantity (EOQ) models, simultaneously taking into account the comprehensive emission model, consumer environmental consciousness, and carbon policies. We then optimized the sustainability level and EOQ using the simulation method. Furthermore, we performed a regression analysis on the carbon policy effects on sustainability level, profit, and emission. Moreover, using the regression models, we estimated and discussed the optimal policy parameters from the perspective of social welfare maximization. The results indicate that the carbon cap-and-trade policy is superior to carbon cap and tax policies. Under carbon cap and tax policies, the tougher the carbon policy, the higher the sustainability level and the lower the profit and carbon emission. Meanwhile, under the carbon cap-and-trade policy, the carbon trading price is the decisive factor that affects the sustainability level, enterprises' profit, and carbon emission; the carbon cap has a positive regulatory effect on profit.

\section{Introduction}

In recent years, global warming and climate change have created increasing awareness of environmental issues among people [1]. Moreover, carbon emission is regarded as the main contributor to global warming and climate change [2]. Due to the frequent occurrences of natural disasters, many countries and regional organizations have passed carbon emission regulations to prevent enterprises from excessively discharging emissions into the air [3]. In general, governments often adopt three policies, namely, carbon cap, tax, and cap-and-trade policies, to reduce carbon emission [4]. For example, the US Congress carries out a carbon cap policy [5]. Meanwhile, the carbon tax policy is adopted in Denmark, Japan, Ireland, and Finland, and the cap-and-trade policy is adopted in Norway, Switzerland, Sweden, Italy, Slovenia, UK, USA, Canada, and China $[3,6]$. At the same time, the public environmental consciousness and social responsibility are increasing with more frequent occurrence of extreme weather events [7], and sustainable consumption is becoming more and more popular all over the world. The idea of carbon label is used to identify the sustainability level of a product. For instance, Walmart has requested its 100,000 suppliers to complete the carbon footprint verification and labeled their products with colors according to the carbon footprints [8]. The sustainability level of the product enables environmental-conscious consumers to select products with the smallest carbon footprints. The higher the consumer environmental consciousness is, the more the customers are willing to accept sustainable 
products even with a higher price $[9,10]$. The European Commission surveys show that $83 \%$ of the Europeans express concern about the carbon emission of products when buying them [11]. The Environmental Protection Ministry of China has launched a pilot project to arouse the public's environmental consciousness by attaching carbon labels and certifying sustainable products [9]. Enhanced environmental awareness means familiarity with the public with the ideas of carbon reduction and sustainable development [3].

In this context, the dual effects of governments and the public cause more stressful and challenging enterprise operations. With the increasing consumer environmental awareness, sustainable technology is an effective way for enterprises to achieve a competitive and commercial advantage [8] and enhance environmental sustainability [12]. Sustainable investment can cut down the carbon emission in the supply chain [13] and improve environmental sustainability and enterprises' competitiveness in the long run [14]. However, enterprises should invest in sustainable operations when adopting sustainable technology, which may lead to a change in their cost structure [8]. Hence, determining an appropriate level of sustainability is a primary concern for enterprises. To meet governments' carbon regulations, enterprises have to adjust their operations' objective from economy to environment. By nature, emission from supply chain operations exceeds $20 \%$ of the total global emission [5], and production, inventory, and transportation activities contribute to sustainability problems in enterprises' operations [15]. In particular, inventory activity is responsible for $11 \%$ of the carbon emission from the logistics sector. For example, by optimizing inventory operations, Hewlett-Packard decreased its carbon emission from 26.1 tonnes to 18.3 tonnes in 2010 [4]. Moreover, transportation accounts for around 5\% of the world's carbon emission [16], which is considered one of the principal sources of carbon emission [15]. The carbon emission generated from the inventory and transportation process is mainly determined by inventory control decisions and transportation scheduling [17]. The interaction of trade-off between inventory and transportation indicates that their integrated optimization is needed to reduce costs and carbon emission [18]. When enterprises adopt sustainable technology, market demand and cost structure will change according to the product's sustainability level. These changes will influence the inventory control decision and transportation scheduling, thereby influencing costs and carbon emission in logistics. In turn, the inventory-transportation scheduling will affect the marginal cost of sustainable investment, thus affecting the decision of sustainability level. Therefore, enterprises need joint decisions on sustainability level and inventory-transportation solutions to satisfy the carbon emission requirements set by the governments.

As far as our knowledge from the literature review, a few studies have attempted to optimize sustainability level and inventory-transportation scheduling simultaneously. For instance, Toptal et al. [19] and Huang et al. [3] developed EOQ models with sustainable investment. However, they did not consider consumer environmental awareness; that is, the demand in their models was constant and did not vary with the sustainability level. In this study, inventorytransportation models that consider consumer environmental awareness and sustainable investment under carbon cap, tax, and cap-and-trade policies were investigated. Furthermore, a comprehensive fuel consumption function is integrated into these models to calculate the costs and emissions in transportation, which can improve reliability and applicability in optimization [20]. We focus on investigating the following questions:

(1) How do enterprises decide sustainability level and inventory-transportation scheduling simultaneously under carbon cap, tax, and cap-and-trade policies?

(2) How do carbon cap, tax, and cap-and-trade policies affect enterprises' sustainability level, profit, and emission?

(3) How do governments set policy parameters to harmonize economic and environmental objectives?

The rest of this paper is organized as follows. The relevant literature is presented in Section 2. Model assumptions and notations are proposed in Section 3. The optimization models of the integrated sustainability level and inventorytransportation problem under carbon cap, tax, and cap-andtrade policies are explored and solved using the simulation solution method in Section 4. Then, the results of simulations and the effect of carbon policies on sustainability level and enterprises' performance are presented in Section 5. Policy parameters set by governments are estimated and discussed in Section 6. Finally, a conclusion is presented in Section 7 .

\section{Literature Review}

Integrated inventory-transportation model incorporates inventory and transportation decisions simultaneously because of their trade-off. Earlier models aimed to maximize the overall total costs of inventory and transportation [21] without taking into account carbon emission. The classical economic order quantity (EOQ) was the first integrated inventory-transportation model introduced by Ford W. Harris in 1913. Since then, increasing numbers of scholars have extended the integrated inventory-transportation model in several ways. In integrated inventorytransportation models, they analyzed different demand functions, such as constant [3, 19, 22], random [20, 23], linear [24], quadratic [25], and time-varying demands [1]. The logistics network has been expanded from a singlesingle type to single-many [26], many-single [27], and many-many forms [20, 23]. For the decision level, the existing research mainly focuses on the tactical level problem $[20,23,28-30]$, with few researchers considering strategic level problem [31]. In terms of the product, the existing research can be divided into the following categories: single product [5] and multiple products [20,32]. Some researchers also consider other characters in the integrated inventorytransportation model. For example, Alım and Beullens [33] integrated a flexible delivery option into the inventorytransportation model for an online sales firm. Meanwhile, 
Gautam et al. [34] jointly optimize the number of shipments and quantities of orders with defect management.

Following the sustainable development, the amount of literature on the integrated inventory-transportation problem considering environmental factors has increased rapidly in recent years. Benjaafar et al. [18] examined a simplified inventory model to explore the impacts of operations decisions on carbon emission. Meanwhile, Soysal et al. [23] explored an inventory routing problem with a comprehensive emissions model in transportation. The results indicated that horizontal collaboration decreases the costs and emissions in logistics. Biuki et al. [35] integrated the economic, ecological, and societal aspects into a location-inventory routing model. Moreover, Bouchery, et al. [16] presented an EOQ model that considers vehicle capacities to provide sufficient conditions that ensure a decrease in costs and carbon emission. The joint decision on inventory and transportation under carbon policies is a hot research topic. Considering carbon tax policy, Wang et al. [30] developed an inventory-transportation model in refined oil logistics. Xu et al. [36] constructed nonlinear models to optimize inventory and transportation strategy for perishable items under carbon tax and carbon cap-and-trade regulations. Meanwhile, Micheli and Mantella [20] extended the model of Soysal et al. [23] with a heterogeneous fleet under carbon cap, carbon tax, and carbon cap-and-trade regulations; they ignored the emissions associated with inventory. Moreover, Tang et al. [17] examined the effect of controlling carbon emission in inventory-transportation management with stochastic demand. They analyzed three carbon regulations, namely, carbon tax, cap-and-trade, and carbon offset. Under the cap-and-trade scheme, Hua et al. [37] extended the classical EOQ model with carbon emission and proved that the optimal order quantity is between the classical EOQ model and the model that minimizes carbon emission. Furthermore, Konur and Schaefer [5] investigated the EOQ model with less-than-truckload and truckload transportation under carbon tax and cap, cap-and-trade, and capand-offset regulations. Chen et al. [38] used EOQ models under various environmental regulations to illustrate the conditions where emissions may be reduced and the relative reduction in emissions is greater than the relative increase in cost. Meanwhile, Liao and Deng [39] extended an EOQ model with uncertain demand under carbon tax regulation, and the result showed that increasing carbon tax will decrease profit margins and alter the optimal order decisions. Finally, Rabta [29] presented an EOQ model in a circular economy and proposed various relationships (linear and nonlinear) between the circularity level and demand, and cost and selling price.

In the context of a sustainable economy, consumer environmental awareness is integrated into a supply chain optimization model. Yu et al. [40] developed an optimization model under oligopolistic competition, and their results show that manufacturers could promote a product's sustainability level due to an increase in consumer environmental awareness. Moreover, to analyze the effect of carbon tax price on carbon emission, Hovelaque and Bironneau [28] explored an EOQ model with demand dependent on price and carbon emission in production and logistics activities. Meanwhile, Zhang et al. [41] investigated the effect of consumer environmental awareness on channel coordination and order quantities. Cheng et al. [8] integrated carbonlabeling scheme into game-theoretic models between a manufacturer and a retailer to investigate the impact of consumer environmental awareness on supply chain performance. Consumer environmental awareness increases market demand or sale price, which drives manufacturers to adopt clean technology and thus increase the sustainability level of product. Hence, integrating clean technology or sustainable investment into supply chain activities has also become a research hotspot. Drake et al. [42] addressed the technology choice problem under carbon tax and cap-andtrade policies. Their results revealed that the expected profit under the cap-and-trade policy is greater than that under carbon tax policy. Meanwhile, Tao and Xu [43] examined an EOQ model to investigate the effect of consumer environmental awareness on optimal order quantity, emission level, and total costs under carbon tax and carbon cap-and-trade regulations. Toptal et al. [19] investigated an EOQ model considering green technology under carbon tax, cap, and cap-and-trade policies. The results revealed that green technology can simultaneously reduce costs and carbon emissions. Moreover, by extending the model, Huang et al. [3] developed green technology to determine the green investment amount, delivery quantity, and optimal production quantity under the same regulations. Dong et al. [13] integrated sustainable investment into order quantity decision with stochastic demand under the carbon cap-andtrade policy. They indicated that sustainable investment has a major impact on the performance of supply chain. Under a carbon tax regulation, Cheng et al. [8] explored a sustainable investment decision-making model using Bayesian information updating. Furthermore, to explore the effects of the government subsidy coefficient on the sustainability level and the retail price, Su et al. [44] examined a green supply chain model under different government subsidies.

This study points out three research gaps on this topic: (1) studies extending classical EOQ models by considering sustainable investment and consumer environmental awareness are scarce. Tao and $\mathrm{Xu}$ [43] only considered consumer environmental awareness, whereas Toptal et al. [19] and Huang et al. [3] only considered sustainable investment. Meanwhile, Dong et al. [13], Cheng et al. [10], and Su et al. [44] considered them both; however, they did not consider inventory and transportation activities in their models. (2) In those EOQ models, transportation cost and emission are assumed to have fixed values or piecewise functions, giving a less accurate estimation of transportation cost and emission. (3) When considering carbon policies, the literature focuses on the sensitivity analysis of policy parameters. There are few studies on deciding appropriate policy parameters from the government perspective.

To conclude, our study adds to the literature on the integrated inventory-transportation model by (1) extending EOQ model with sustainable investment and consumer environmental awareness simultaneously under different carbon emission regulations (i.e., cap, tax, and cap-and- 
trade) and (2) employing a comprehensive fuel consumption function, on the basis of factors such as vehicle type, vehicle load, vehicle speed, and traveled distance, to compute transportation cost and emission. The explicit consideration of fuel consumption ensures a more accurate estimation of transportation cost and emission [20,23]. This study also contributes to the literature by (3) developing regression models to analyze the effect of policy parameters on sustainability level, profit, and emission, and estimate optimal policy parameters based on maximizing social welfare. Table 1 presents the literature positioning of the present paper.

\section{Model Assumptions and Notations}

We consider an enterprise that manufactures a sustainable item and sells the product on its own salespoint. The enterprise determines the sustainability level and controls the inventory and transportation for the item. The main forces driving sustainable investment are governments' carbon policies and consumers' environmental awareness. The market demand is dependent on the sustainability level, which affects the inventory control and transportation decision. The enterprise needs joint decisions on sustainability level and EOQ to maximize its profit and satisfy carbon policies. We consider three carbon regulations: cap, tax, and cap-and-trade. The major notations used in the models are summarized in Table 2. The models are developed under the following assumptions:

(1) The enterprise assumes the basic EOQ settings: the demand is uniform and continuous; no shortage is allowed; the order lead time is known and constant; the inventory replenishment is completed instantaneously; the ordering cost per time is constant and independent of order quantity; and the holding cost is a linear function of inventory [43]. In addition, the production cost of each unit is constant and independent of the sustainability level.

(2) We assume that the sustainability level only describes the carbon emission in the manufacturing process but does not include the carbon emission in transportation and inventory. Sustainability level $S$ is a dimensionless indicator ranging from 0 to 1 [29]. The sustainability level $S$ is determined by the manufacturer and measured by equation (1), where $e_{0}$ is the carbon emission in production, $a$ is the base carbon emission per unit when $S=0$, and $b$ is the minimum carbon emission when $S=1$ :

$$
S=\frac{a-e_{0}}{a-b}
$$

(3) We assume that the sustainable investment cost is a quadratic function $[10,13]$; that is, $\delta S^{2} / 2$, where $\delta$ is the sustainable investment coefficient. The cost and cost growth rate of sustainable investment increase monotonously with the sustainability level.

(4) We assume a linear demand function affected by the sustainability level; that is, $D=D_{0}+\rho S$, where $\rho$ is the coefficient of the sustainable effect on the increasing demand [29] and $D_{0}$ is the potential demand per year when $S=0$, or $\rho=0$.

(5) We assume a limited, capacitated, and homogeneous fleet. Moreover, to compute the cost and carbon emission in transportation, we assume comprehensive fuel consumption [20,23]. Given a traveled distance $d$ and a vehicle speed $f$, the fuel consumption, denoted by FC, is computed by equation (2), where $\xi$ is fuel-to-air mass ratio, $k_{e}$ is engine friction factor, $N_{e}$ is engine speed, $V_{e}$ is engine displacement, $\boldsymbol{\omega}$ is efficiency parameter for diesel engines, $A_{f}$ is frontal surface area, $\varepsilon$ is vehicle drive train efficiency, $c_{d}$ is coefficient of aerodynamic drag, $\alpha$ is air density, $g$ is gravitational constant, $\varphi$ is road angle, $c_{r}$ is coefficient of rolling resistance, $\mu$ is curtweight, $\kappa$ is heating value of a typical diesel fuel, and $V$ is payload:

$$
\mathrm{FC}=\xi\left(\frac{\left(k_{e} N_{e} V_{e} d / f\right)+\left(0.5 c_{d} \alpha A_{f} d f^{2} /(1000 \bowtie \varepsilon)\right)+d g\left(\left(\sin \varphi+c_{r} \cos \varphi\right)(\mu+V) /(1000 \bowtie \varepsilon)\right)}{(\kappa \psi)}\right)
$$

Let $\lambda=(\xi /(\kappa \psi)), \quad y=k_{e} N_{e} V_{e}, \quad \gamma=(1 /(1000 \omega \varepsilon))$, $B=0.5 c_{d} \alpha A_{f}$, and $\sigma=g\left(\sin \varphi+c_{r} \cos \varphi\right)$; then $F C$ $=\lambda\left((y \mathrm{~d} / f)+\mathrm{d} \gamma B f^{2}+\mathrm{d} \gamma \sigma(\mu+V)\right)$. Let $\tau_{1}=(\lambda \mathrm{d} y / f)$ $+\lambda \mathrm{d} \gamma\left(B f^{2}+\mu \sigma\right)$ and $\tau_{2}=\lambda \mathrm{d} \gamma \sigma$; then the vehicle transportation cost is $\vartheta k \tau_{1}+\vartheta \tau_{2} Q$, where $k$ is the number of vehicles, $Q$ is order quantity, and $\vartheta$ is fuel price. The carbon emission in transportation is $\theta k \tau_{1}+\theta \tau_{2} Q$, where $\theta$ denotes fuel conversion factor.

\section{Optimization Model}

4.1. Base Case Model $\left(M_{0}\right)$. The base case model, denoted by $M_{0}$, represents the case where there is no carbon policy. The enterprise's goal is to maximize profits. Without any carbon policy in place, the average annual profit is given by equation (3), where $k=\lceil Q / L\rceil$. In equation (3), the first, second, third, fourth, fifth, and sixth terms are sales income, manufacturing cost, sustainable investment cost, inventory 
TABLE 1: The literature positioning of this paper.

\begin{tabular}{|c|c|c|c|c|c|c|c|}
\hline \multirow{2}{*}{ Papers } & \multirow{2}{*}{$\begin{array}{l}\text { Sustainable } \\
\text { investment }\end{array}$} & \multirow{2}{*}{$\begin{array}{c}\text { Consumer } \\
\text { environmental } \\
\text { awareness }\end{array}$} & \multirow{2}{*}{$\begin{array}{l}\text { Comprehensive fuel } \\
\text { consumption }\end{array}$} & \multicolumn{3}{|c|}{$\begin{array}{l}\text { Carbon emission } \\
\text { regulation }\end{array}$} & \multirow{2}{*}{$\begin{array}{c}\text { Decision on policy } \\
\text { parameters }\end{array}$} \\
\hline & & & & Cap & $\operatorname{Tax}$ & $\begin{array}{l}\text { Cap-and- } \\
\text { trade }\end{array}$ & \\
\hline $\begin{array}{l}\text { Konur and Schaefer } \\
\text { [5], Tang et al. }\end{array}$ & & & & $\sqrt{ }$ & $\sqrt{ }$ & $\sqrt{ }$ & \\
\hline Dong et al. [13] & $\sqrt{ }$ & $\sqrt{ }$ & & & & $\sqrt{ }$ & \\
\hline Soysal et al. [23] & & & $\sqrt{ }$ & & & & \\
\hline $\begin{array}{l}\text { Micheli and } \\
\text { Mantella [20] }\end{array}$ & & & $\sqrt{ }$ & $\sqrt{ }$ & $\sqrt{ }$ & $\sqrt{ }$ & \\
\hline Tao and $\mathrm{Xu}$ [43] & & $\sqrt{ }$ & & $\sqrt{ }$ & $\sqrt{ }$ & $\sqrt{ }$ & \\
\hline $\begin{array}{l}\text { Toptal et al. [19], } \\
\text { Huang et al. [3] }\end{array}$ & $\sqrt{ }$ & & & $\sqrt{ }$ & & $\sqrt{ }$ & \\
\hline $\begin{array}{l}\text { Cheng et al. [8], } \\
\text { Su et al. [44] }\end{array}$ & $\sqrt{ }$ & $\sqrt{ }$ & & & & & \\
\hline This paper & $\sqrt{ }$ & $\sqrt{ }$ & $\sqrt{ }$ & $\sqrt{ }$ & $\sqrt{ }$ & $\sqrt{ }$ & $\sqrt{ }$ \\
\hline
\end{tabular}

TABLe 2: Main notations.

\begin{tabular}{|c|c|}
\hline Parameters & Meaning \\
\hline$A$ & Fixed cost of inventory replenishment \\
\hline$h$ & Holding cost per unit per year held in inventory \\
\hline$c_{0}$ & Manufacturing cost per unit \\
\hline$c_{t}$ & Transportation cost, $c_{t}=\vartheta k \tau_{1}+\vartheta \tau_{2} Q$ \\
\hline$L$ & Vehicle capacity \\
\hline$P$ & Sale price \\
\hline$D_{0}$ & Potential demand per year when $S=0$ \\
\hline$\rho$ & Coefficient of the effect of sustainability on demand \\
\hline$\delta$ & Coefficient of sustainable investment \\
\hline$D$ & Actual demand per year, $D=D_{0}+\rho S$ \\
\hline$\widehat{A}$ & Carbon emission amount due to inventory replenishment \\
\hline$\widehat{h}$ & Carbon emission amount due to holding a unit inventory per year \\
\hline$\widehat{c_{t}}$ & Carbon emission amount due to transportation, $\widehat{c}_{t}=\theta k \tau_{1}+\theta h \tau_{2} Q$ \\
\hline$n$ & Carbon policy index: $n=0$ for no carbon, $n=1$ for cap, $n=2$ for tax, and $n=3$ for cap-and-trade policies \\
\hline$C_{a}$ & Carbon emission cap per year \\
\hline$C_{p}$ & Carbon emission trading price per ton \\
\hline$C_{T}$ & Carbon tax price per ton \\
\hline SW & Social welfare \\
\hline$U_{e c}$ & Economic utility \\
\hline$U_{e n}^{e c}$ & Environmental utility \\
\hline \multicolumn{2}{|l|}{ Decision variables } \\
\hline Q & Order quantity \\
\hline S & Sustainability level \\
\hline \multicolumn{2}{|l|}{ Functions } \\
\hline$E(Q, S)$ & Average annual carbon emission function \\
\hline$Z(Q, S)$ & Average annual profit function \\
\hline
\end{tabular}

replenishment cost, inventory holding cost, and transportation cost, respectively:

$$
\begin{aligned}
Z_{0}(Q, S)= & P\left(D_{0}+\rho S\right)-c_{0}\left(D_{0}+\rho S\right)-\frac{\delta S^{2}}{2}-\frac{A\left(D_{0}+\rho S\right)}{Q} \\
& -\frac{h Q}{2}-\left(\frac{k \vartheta \tau_{1}\left(D_{0}+\rho S\right)}{Q}+\vartheta \tau_{2}\left(D_{0}+\rho S\right)\right),
\end{aligned}
$$

where $Z_{0}(Q, S)$ is a discontinuous function, and the optimal solution $(Q, S)$ cannot be directly obtained by the first-order partial derivative. We design a two-stage optimization method to solve the problem. First, we assume that the sustainability level is given by the enterprise, under which we solve the optimal order quantity problem. Second, we obtain the optimal $S$ by the simulation method. In the following analysis, the optimal order quantity problems under different carbon regulations are solved in Sections 4.1-4.4. Meanwhile, the simulation method for solving the optimal $S$ is analyzed in Section 4.5. 
Given $S$, the optimal EOQ $Q_{0}^{*}$ that maximizes $Z_{0}(Q, S)$ also cannot be determined using the first-order derivative. $Z_{0}(Q, S)$, especially, is a piecewise continuous function such that each piece is in the form of equation (2) over a given quantity range of length $L$. Obviously, the sum of the first five terms of $Z_{0}(Q, S)$ is an EOQ-type convex function of $Q$ with a maximum at $q_{\text {eoq }}=\sqrt{\left(2 A\left(D_{0}+\rho S\right) / h\right)}$. For each fixed positive integer $k$, the sixth term is a decreasing convex function of $Q$ over $(k-1) L<Q \leq k L$. Based on these characteristics of $Z_{0}(Q, S)$, the following properties are verified [22].

Property 1. Let $Q_{0}^{k}=\sqrt{\left(2\left(A+k \vartheta \tau_{1}\right)\left(D_{0}+\rho S\right) / h\right)}, \quad k=1$, $2, \ldots$ If $(k-1) L<Q_{0}^{k} \leq k L, Q_{0}^{k}$ is realizable.

Property 2. Define $i$ to be the unique integer such that $(i-1) L<q_{\text {eoq }} \leq i L$. For all $k \leq i-1, Z_{0}(Q, S)$ is increasing over $(k-1) L<Q \leq k L$ and $Q_{0}^{k}$ is not realizable.

Property 3. If $k \geq i$, then $Z_{0}(Q, S) \leq Z_{0}(k L, S)$ for $Q \geq k L$.

Property 4. If $Q_{0}^{i} \geq i L$, then $Z_{0}(Q, S)$ is increasing over $(i-1) L<Q \leq i L$. If $Q_{0}^{i}<i L$, then $Z_{0}(Q, S)$ is increasing over $(i-1) L<Q \leq Q_{0}^{i}$ and decreasing over $Q_{0}^{i}<Q \leq i L$.
From Properties 1-4, the optimal EOQ $Q_{0}^{*}$ is defined by the following corollary.

Corollary 1. Given the sustainability level $S$,

$Q_{0}^{*}=\arg \max \left\{Z\left(\min \left\{Q_{0}^{i+1},(i+1) L\right\}, S\right), Z(i L, S)\right\} . Q_{0}^{*}$ can be determined by the following algorithm:

Step 1. Compute $q_{\text {eoq }}=\sqrt{\left(2 A\left(D_{0}+\rho S\right) / h\right)}$ and $i=\left\lceil q_{\text {eoq }} / L\right\rceil$.

Step 2. Compute $Q_{0}^{i}=\sqrt{\left(2\left(A+i \vartheta \tau_{1}\right)\left(D_{0}+\rho S\right) / h\right)}$. If $Q_{0}^{i} \geq i L$, let $Q_{0}^{i}=i L$.

Step 3.Compute and compare $Z\left(Q_{0}^{i}, S\right)$ and $Z_{0}((i-1) L, S)$. Select the one that yields the maximum profit as the optimal $Q_{0}^{*}$, and stop.

4.2. Model under Carbon Cap Regulation $\left(M_{1}\right)$. Under a cap regulation, the enterprise is subject to an upper bound on the total average annual carbon emission. The enterprise's problem is to find the sustainability level of production and the optimal order quantity to maximize the average annual total profit without exceeding the emission cap $C_{a}$. This problem can be formulated as follows:

$$
\begin{array}{ll}
(M 1): \max & Z_{1}(Q, S)=\left(P-c_{0}-\vartheta \tau_{2}\right)\left(D_{0}+\rho S\right)-\frac{\delta S^{2}}{2}-\frac{\left(A+k \vartheta \tau_{1}\right)\left(D_{0}+\rho S\right)}{Q}-\frac{h Q}{2} \\
\text { s.t. } & E(Q, S)=\frac{\left(\widehat{A}+k \theta \tau_{1}\right) D_{0}+\rho S}{Q}+\frac{\widehat{h} Q}{2}+\left(a+(b-a) S+\theta \tau_{2}\right)\left(D_{0}+\rho S\right) \leq C_{a} \\
& Q \geq 0 .
\end{array}
$$

$Z_{1}(Q, S)$ and $E(Q, S)$ are discontinuous functions and should be analyzed simultaneously to find the optimal solution to $M 1$, which is denoted by $Q_{1}^{*}$. Feasible solutions exist for M1 when the minimum of $E(Q, S)$ is lager than $C_{a}$. Similar to $Z_{1}(Q, S)$, each piece of the $E(Q, S)$ function is an EOQ type. According to Corollary 1, the optimal emission order quantity $\widehat{Q}^{*}$ and the least emission $\widehat{E}^{*}$ can be determined by the following algorithm $[22,45]$ :

$$
\begin{aligned}
& \text { Step 1. Compute } \widehat{q}_{\text {eoq }}=\sqrt{\left(2 \widehat{A}\left(D_{0}+\rho S\right) / \widehat{h}\right)} \text { and } \\
& i=\left\lceil\widehat{q}_{\text {eoq }} / L\right\rceil \text {. }
\end{aligned}
$$

Step 2. Compute $\widehat{Q}^{i}=\sqrt{\left(2\left(\widehat{A}+i \vartheta \tau_{1}\right)\left(D_{0}+\rho S\right) / \widehat{h}\right)}$. If $\widehat{Q}^{i} \geq i L$, let $\widehat{Q}^{i}=i L$.

Step 3. Compute and compare $E\left(\widehat{Q}^{i}, S\right)$ and $E((i-1) L, S)$. If $\quad E\left(\widehat{Q}^{i}, S\right) \leq E((i-1) L, S)$, $\widehat{Q}^{*}=\widehat{Q}^{i}, \widehat{E}^{*}=E\left(\widehat{Q}^{i}, S\right) ; \quad$ else, $\quad \widehat{Q}^{*}=(i-1) L$, $\widehat{E}^{*}=E((i-1) L, S)$, and stop.

We assume that $C_{a} \geq \widehat{E}^{*}$; that is, feasible order quantities exist for M1. Given $S$, the feasible solution consists of all pairs $\left(Q_{1}, S\right)$ such that $q_{1}^{i} \leq Q_{1} \leq q_{2}^{i}$, where

$$
\begin{aligned}
& q_{1}^{i}=\frac{C_{a}-\left(a+(b-a) S+\theta \tau_{2}\right)\left(D_{0}+\rho S\right)-\sqrt{\left(C_{a}-\left(a+(b-a) S+\theta \tau_{2}\right)\left(D_{0}+\rho S\right)\right)^{2}-2 \widehat{h}\left(\widehat{A}+i \theta \tau_{1}\right)\left(D_{0}+\rho S\right)}}{\widehat{h}} . \\
& q_{2}^{i}=\frac{C_{a}-\left(a+(b-a) S+\theta \tau_{2}\right)\left(D_{0}+\rho S\right)+\sqrt{\left(C_{a}-\left(a+(b-a) S+\theta \tau_{2}\right)\left(D_{0}+\rho S\right)\right)^{2}-2 \widehat{h}\left(\widehat{A}+i \theta \tau_{1}\right)\left(D_{0}+\rho S\right)}}{\widehat{h}},
\end{aligned}
$$


where $q_{1}^{i}$ and $q_{2}^{i}$ are the two roots of $\left(\widehat{A}+k \theta \tau_{1}\right)$ $\left(D_{0}+\rho S\right) / Q+\widehat{h} Q / 2+\left(a+(b-a) S+\theta \tau_{2}\right)\left(D_{0}+\rho S\right)=C_{a}$. Now, consider the range $((i-1) L, i L]$. When $q_{2}^{i} \leq(i-1) L$ or $q_{1}^{i}>i L$, there is no feasible solution in the range $((i-1) L, i L]$. Otherwise, the feasible range of $Q_{1}$ is $\left[Q_{1}^{i}, Q_{2}^{i}\right], \quad$ where $Q_{1}^{i}=\max \left\{q_{1}^{i},(i-1) L\right\} \quad$ and $Q_{2}^{i}=\min \left\{q_{2}^{i}, i L\right\}$. It is easy to verify that $q_{1}^{1}<q_{1}^{2}<\cdots<q_{1}^{n}<q_{2}^{n}<q_{2}^{n-1}<\cdots<q_{2}^{1}$, and the length of feasible region is decreasing in the number of vehicles $i$. Let $m_{1}$ and $m_{2}$ be defined as the minimum and the maximum number of vehicles, respectively, such that M1 is feasible. $m_{1}$ and $m_{2}$ can be easily determined using the relation $q_{1}^{1}<q_{1}^{2}<\cdots<q_{1}^{n}<q_{2}^{n}<q_{2}^{n-1}<\cdots<q_{2}^{1}$. By the definitions of $m_{1}$ and $m_{2}$, it follows that $Q_{1} \in\left[Q_{1}^{m_{1}}, Q_{2}^{m_{2}}\right]$ [5].

Recall form Property 2 that $i$ is the unique integer, such that $(i-1) L<q_{\mathrm{eoq}} \leq i L$. The following corollary summarizes the optimal solution for M1 [5].

Corollary 2. Given the sustainability level $S$ and supposing that M1 is feasible,

(1) if $m_{1} \geq i$, then $Q_{1}^{*}=Q_{0}^{i}$ if $Q_{0}^{i} \in\left[Q_{1}^{m_{1}}, Q_{2}^{m_{2}}\right] ; Q_{1}^{*}=$ $Q_{1}^{m_{1}}$ if $Q_{0}^{i}<Q_{1}^{m_{1}}$; and $Q_{1}^{*}=Q_{2}^{m_{1}}$ if $Q_{0}^{i}>Q_{2}^{m_{1}}$

(2) if $m_{2} \leq i-1$, then $Q_{1}^{*}=Q_{2}^{m_{1}}$, if $m_{1}=m_{2}$; and $Q_{1}^{*}=$ $\arg \max \left\{Z_{1}\left(Q_{2}^{m_{2}-1}, S\right), Z_{1}\left(Q_{2}^{m_{2}}, S\right)\right\}$ if $m_{1} \neq m_{2}$

(3) if $\quad m_{1} \leq i-1<i \leq m_{2}$, then $Q_{1}^{*}=\arg \max$ $\left\{Z_{1}((i-1) L, S), Z_{1}\left(\min \left\{Q_{0}^{i}, Q_{2}^{i}\right\}, S\right)\right\}$

From Corollary 2, $Q_{1}^{*}$ can be determined by the following algorithm:
Step 1. Compute $q_{\text {eoq }}=\sqrt{\left(2 A\left(D_{0}+\rho S\right) / h\right)}$ and $i=\left\lceil q_{\text {eoq }} / L\right\rceil$.

Step 2. Compute $Q_{0}^{i}=\sqrt{\left(2\left(A+i \vartheta \tau_{1}\right)\left(D_{0}+\rho S\right) / h\right)}$.

Step 3. Let $j=1,2, \ldots$, and set $i=j$ in equations (5) and (6) to compute $q_{1}^{j}$ and $q_{2}^{j}$. Let $m_{1}$ be defined as the minimum integer such that $\left[Q_{1}^{j}, Q_{2}^{j}\right] \neq \varnothing$, and let $m_{2}$ be defined as the maximum integer such that $\left[Q_{1}^{j}, Q_{2}^{j}\right] \neq \varnothing$.

Step 4. Set $Q_{1}^{m_{1}}=\max \left\{q_{1}^{m_{1}},\left(m_{1}-1\right) L\right\}, Q_{1}^{m_{2}}=\max$ $\left\{q_{1}^{m_{2}},\left(m_{2}-1\right) L\right\}, Q_{2}^{m_{1}}=\min \left\{q_{2}^{m_{1}}, m_{1} L\right\}$, and $Q_{2}^{m_{2}}=$ $\min \left\{q_{2}^{m_{2}}, m_{2} L\right\}$. If $m_{1} \geq i$, go to Step 5. If $m_{2} \leq i-1$, go to Step 6. Otherwise, go to Step 7.

Step 5. If $Q_{1}^{m_{1}}>Q_{0}^{i}, Q_{1}^{*}=Q_{1}^{m_{1}}$. If $Q_{2}^{m_{1}}<Q_{0}^{i}, Q_{1}^{*}=Q_{2}^{m_{1}}$. Otherwise, $Q_{1}^{*}=Q_{0}^{i}$ and stop.

Step 6. If $m_{1}=m_{2}, Q_{1}^{*}=Q_{2}^{m_{1}}$. Otherwise, compute the profit for $Q=Q_{2}^{m_{2}-1}$ and $Q=Q_{2}^{m_{2}}$. Select the one that yields the maximum profit as the optimal $Q_{1}^{*}$, and stop.

Step 7. Let $Q_{1}^{\prime}=\min \left\{Q_{0}^{i}, Q_{2}^{i}\right\}$. Compute the profit for $Q=Q_{1}^{\prime}$ and $Q=(i-1) L$. Select the one that yields the maximum profit as the optimal $Q_{1}^{*}$, and stop.

4.3. Model under Carbon Tax Regulation $\left(M_{2}\right)$. Under a tax regulation, the enterprise pays $C_{T}$ monetary units in taxes for unit carbon emission. The enterprise's objective is to maximize average annual total profit without restriction on the maximum carbon emission and its problem can be formulated as follows:

$$
\begin{aligned}
(M 2): \max & Z_{2}(Q, S)=\left(P-c_{0}-\vartheta \tau_{2}\right)\left(D_{0}+\rho S\right)-\frac{\delta S^{2}}{2}-\frac{\left(A+k \vartheta \tau_{1}\right)\left(D_{0}+\rho S\right)}{Q}-\frac{h Q}{2}-C_{T} E(Q, S) \\
\text { s.t. } & E(Q, S)=\frac{\left(\widehat{A}+k \theta \tau_{1}\right)\left(D_{0}+\rho S\right)}{Q}+\frac{\widehat{h} Q}{2}+\left(a+(b-a) S+\theta \tau_{2}\right)\left(D_{0}+\rho S\right)
\end{aligned}
$$

$Q \geq 0$

Substituting $E(Q, S)$ into $Z_{2}(Q, S)$, then we have

$$
\begin{aligned}
Z_{2}(Q, S)= & \left(P-c_{0}-\tau_{2}\left(\vartheta+C_{T} \theta\right)\right. \\
& \left.-C_{T}(a+(b-a) S)\right)\left(D_{0}+\rho S\right)-\frac{\delta S^{2}}{2} \\
& -\frac{\left(A+C_{T} \widehat{A}+k \tau_{1}\left(\vartheta+C_{T} \theta\right)\right)\left(D_{0}+\rho S\right)}{Q} \\
& -\frac{\left(h+C_{T} \widehat{h}\right) Q}{2} .
\end{aligned}
$$

Equation (8) indicates that $Z_{2}(Q, S)$ has the same function structure as $Z_{0}(Q, S)$. Hence, the following corollary is obtained from Properties $1-4$ to find the optimal EOQ, which is denoted by $Q_{2}^{*}$.
Corollary 3. Given the sustainability level $S$, $Q_{2}^{*}=\arg \max \left\{Z\left(\min \left\{Q_{2}^{i}, i L\right\}, S\right), Z((i-1) L, S)\right\} \cdot Q_{2}^{*}$ can be determined by the following algorithm:

$$
\begin{array}{lrr}
\text { Step } & \text { Compute } & q_{2 \text { eoq }}= \\
\sqrt{\left(\left(2\left(A+C_{T} \widehat{A}\right)\left(D_{0}+\rho S\right)\right) /\left(h+C_{T} \widehat{h}\right)\right)} & \text { and } i=\left\lceil q_{2 e o q} /\right. \\
L\rceil . &
\end{array}
$$

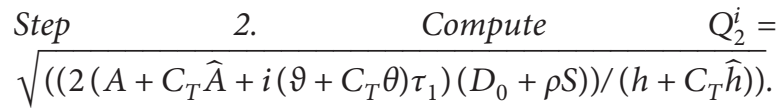
If $Q_{2}^{i} \geq i L$, let $Q_{2}^{i}=i L$.

Step 3. Compute and compare $Z_{2}\left(Q_{2}^{i}, S\right)$ and $Z_{2}((i-1) L, S)$. Select the one that yields the maximum profit as the optimal $Q_{2}^{*}$, and stop. 
4.4. Model under Carbon Cap-and-Trade Regulation $\left(M_{3}\right)$. Under a cap-and-trade regulation, the enterprise is subject to an emission cap on the total carbon emission. If the carbon emission is more than or lower than the cap, the enterprise can buy carbon emission permits or sell extracarbon emission with a carbon emission trading system [19]. Supply and demand are assumed to be always available for buying and selling carbon emissions. The enterprise's problem of deciding the optimal order quantity is formulated as follows:

$$
\begin{aligned}
& (M 3): \max Z_{3}(Q, S)=\left(P-c_{0}-\vartheta \tau_{2}\right)\left(D_{0}+\rho S\right)-\frac{\delta S^{2}}{2}-\frac{\left(A+k \vartheta \tau_{1}\right)\left(D_{0}+\rho S\right)}{Q}-\frac{h Q}{2}-C_{p} x . \\
& \text { s.t. } \quad E(Q, S)=\frac{\left(\widehat{A}+k \theta \tau_{1}\right)\left(D_{0}+\rho S\right)}{Q}+\frac{\widehat{h} Q}{2}+\left(a+(b-a) S+\theta \tau_{2}\right)\left(D_{0}+\rho S\right) . \\
& x=E(Q, S)-C_{a} . \\
& Q \geq 0 .
\end{aligned}
$$

The objective function $Z_{3}(Q, S)$ is translated into equation (13) by substituting $E(Q, S)$ and $x$ into equation (9):

$$
\begin{aligned}
Z_{3}(Q, S)= & \left(P-c_{0}-\tau_{2}\left(\vartheta+C_{p} \theta\right)\right. \\
& \left.-C_{p}(a+(b-a) S)\right)\left(D_{0}+\rho S\right)+C_{p} C_{a}-\frac{\delta S^{2}}{2} \\
& -\frac{\left(A+C_{p} \widehat{A}+k \tau_{1}\left(\vartheta+C_{p} \theta\right)\right)\left(D_{0}+\rho S\right)}{Q} \\
& -\frac{\left(h+C_{p} \hat{h}\right) Q}{2} .
\end{aligned}
$$

Note that $Z_{3}(Q, S)$ follows a similar functional form with $Z_{0}(Q, S)$ and $Z_{2}(Q, S)$. From Properties $1-4$, the optimal EOQ under carbon cap-and-trade regulation, denoted by $Q_{3}^{*}$, can be determined by the following corollary.

Corollary 4. Given the sustainability level $S$, $Q_{3}^{*}=\arg \max \left\{Z\left(\min \left\{Q_{3}^{i}, i L\right\}, S\right), Z((i-1) L, S)\right\} . Q_{3}^{*}$ can be determined by the following algorithm:

$$
\begin{aligned}
& \begin{array}{llc}
\text { Step } & \text { Compute } & q_{3 e o q}= \\
\sqrt{\left(\left(2\left(A+C_{p} \widehat{A}\right)\left(D_{0}+\rho S\right)\right) /\left(h+C_{p} \widehat{h}\right)\right)} & \text { and } i=\left(q_{3 e o q} / L\right) .
\end{array} \\
& \text { Step 2. Compute } \quad Q_{3}^{i}= \\
& \sqrt{\left(\left(2\left(A+C_{p} \widehat{A}+i\left(\vartheta+C_{p} \theta\right) \tau_{1}\right)\left(D_{0}+\rho S\right)\right) /\left(h+C_{p} \widehat{h}\right)\right)} . \\
& \text { If } Q_{3}^{i} \geq i L \text {, let } Q_{3}^{i}=i L \text {. } \\
& \text { Step 3. Compute and compare } Z_{3}\left(Q_{3}^{i}, S\right) \text { and } \\
& Z_{3}((i-1) L, S) \text {. Select the one that yields the maximum } \\
& \text { profit as the optimal } \mathrm{Q}_{3}^{*} \text {, and stop. }
\end{aligned}
$$

4.5. Simulation Method for Optimizing Sustainability Level. Corollaries 1-4 show that the optimal order quantity is dependent on the sustainability level $S$ at any carbon policy case. The optimal sustainability level $S$ cannot be deduced directly. A simulation method is used to seek for the optimal sustainability level $S$ by transforming the continuous variable $S$ into a discrete variable. Considering $0 \leq S \leq 1$, and setting the optimization precision error to $0.001,1001$ feasible solutions exist for $S$, that is, $0,0.001$, $0.002, \ldots, 0.999,1$. At any carbon policy case, the simulation process consists of nine steps, as shown in Figure 1.

Step 1. Set $j=0, Z Z=0, S S=0$.

Step 2. Let $S(j)=j^{*} 0.001$.

Step 3. Given $S(j)$, compute the EOQ using the algorithms of Corollaries 1-4 and obtain $Q(j)$.

Step 4. For the solution pair $(Q(j), S(j))$, compute the profit $Z(j)$ using $Z(Q, S)$.

Step 5. Compare $Z(j)$ and $Z Z$. If $Z(j) \geq Z Z$, go to Step 6. Otherwise, go to Step 7.

Step 6. Let $S S=S(j), Z Z=Z(j)$.

Step 7. Let $j=j+1$.

Step 8. If $j>1000$, go to Step 9. Otherwise, go back to Step 2.

Step 9. Assign SS to the optimal S, and stop.

Let us take the following as an example. Set $A=\$ 150$, $h=\$ 3, \widehat{A}=200 \mathrm{~kg}, \widehat{h}=5 \mathrm{~kg}, \quad P=\$ 0.5 / \mathrm{kg}, \quad c_{0}=\$ 0.2 / \mathrm{kg}$, $a=0.4 \mathrm{~kg}, \quad b=0.1 \mathrm{~kg}, \quad \vartheta=\$ 1.5 / 1, \quad \theta=2.63 \mathrm{~kg} / \mathrm{l}$, $D_{0}=250,000 \mathrm{~kg}, \rho=50,000 \mathrm{~kg}, \delta=\$ 70,000, f=80 \mathrm{~km} / \mathrm{h}$, and $d=500 \mathrm{~km}$. Based on the model of Micheli and Mantella [20], the vehicle parameters are reported as follows: $\xi=1, \quad k_{e}=(0.25 \mathrm{kj} / \mathrm{rev} / \mathrm{l}), \quad N_{e}=38.3 \mathrm{rev} / \mathrm{s}, \quad V_{e}=4.5 \mathrm{l}$, $\varpi=0.45, A_{f}=7 \mathrm{~m}^{2}, \varepsilon=0.45, c_{d}=0.6, \alpha=1.2041 \mathrm{~kg} / \mathrm{m}^{3}$, $9.81 \mathrm{~m} / \mathrm{s}^{2}, \quad \varphi=0, \quad c_{r}=0.01, \quad \mu=3,500 \mathrm{~kg}, \quad \kappa=44$, and $L=4,000 \mathrm{~kg}$. Carbon policy parameters are assumed as follows: the carbon tax price and carbon trading price are $\$ 200 /$ ton, and the cap is $80 \%$ of allowed emissions with respect to the base case when the sustainable investment is not considered. Based on the simulation optimization process shown in Figure 1, the simulation calculations under 


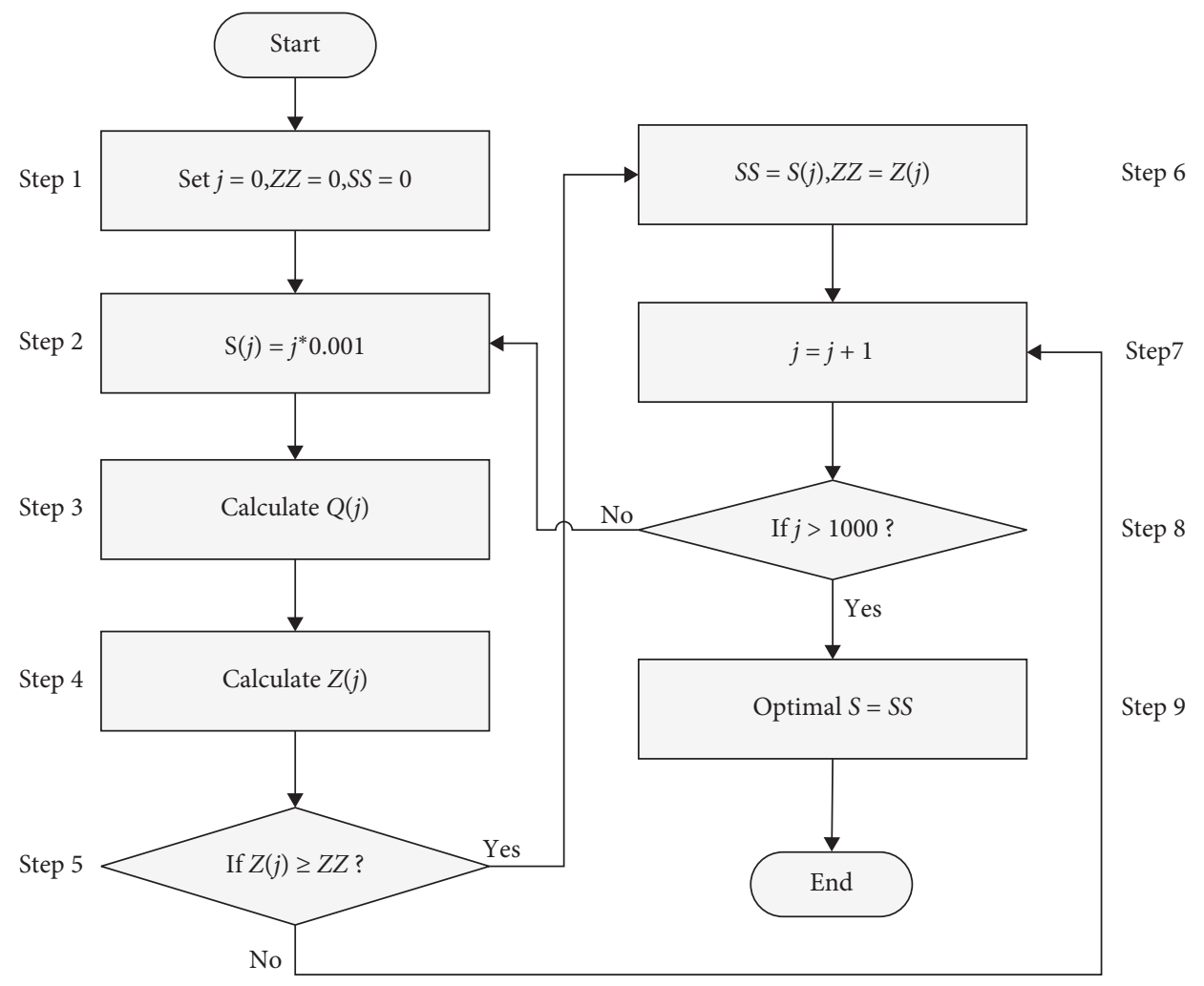

FIgURE 1: Simulation optimization process.

each carbon policy were programmed separately in MATLAB. The optimal sustainability level $S, E O Q Q$, profit $Z$, and carbon emission $E$ are shown in Table 3. The computation time is less than $0.5 \mathrm{~s}$ in all cases, implying the feasibility of the simulation optimization method.

\section{Simulation Analysis}

In this section, we focus on the simulation analysis to explore the effects of carbon emission regulations on sustainability level, profit, and carbon emission. In all of the problem instances, we assume that $d \sim U[100,500] \mathrm{km}$ and $f \sim U[20,80] \mathrm{km} / \mathrm{h}$, where $U[m, n]$ denotes a uniform distribution with bounds $m$ and $n$. The same vehicle parameters are adopted as in Section 4.5 [20]. The fuel price $\vartheta$ is assumed to be $U \$[1,2] / 1$. The emission conversion factor $\theta$ is set equal to $2.63 \mathrm{~kg} / \mathrm{l}$. The cost and carbon emission parameters are randomly generated assuming that $P \sim U \$[0.5,0.6] / \mathrm{kg}, c_{0} \sim U \$[0.2,0.3] / \mathrm{kg}, a \sim U[0.4,0.6] \mathrm{kg}$, $b \sim U[0.1,0.2] \mathrm{kg} . h \sim U \$[1,5] / \mathrm{kg}, D_{0} \sim U[100,500]$ tonne, $\mathrm{A} \sim U \$[50,250], h \sim U \$[2,8]$, and $\widehat{A} \sim U[50,300] \mathrm{kg}$ (similar values are used by Konur and Schaefer [5]). The sustainable parameters $\rho$ and $\delta$ are assumed to be $U\left[0.1 D_{0}, 0.3 D_{0}\right] \mathrm{kg}$ and $U \$[50000,100000]$, respectively. All the above parameters randomly generate 1,000 different parameters and then generate 1,000 different situations through random combination. Based on the previous model solution method and the above data, the simulation method programmed in MATLAB is used to solve the optimal sustainability level, profit, and carbon emission under the three policies, namely, carbon cap, tax, and cap-and-trade.
TABLE 3: Simulation computation results of the example.

\begin{tabular}{lcccc}
\hline Carbon policy & No policy & Cap & Tax & Cap-and-trade \\
\hline$S$ & 0.139 & 0.281 & 0.316 & 0.331 \\
$Q(\mathrm{~kg})$ & 4,000 & 4,000 & 8,000 & 8,000 \\
$Z(\$)$ & 46,971 & 43,348 & 13,362 & 44,816 \\
$E(\mathrm{~kg})$ & 170,767 & 130,413 & 139,371 & 131,840 \\
\hline
\end{tabular}

5.1. Effects of Carbon Cap under Carbon Cap Regulation. Under the carbon cap policy, we use the model $M_{0}$ to calculate the carbon emission when the profit is maximized. Use this carbon emission as a benchmark, and set a carbon cap policy between $50 \%$ and $100 \%$ of this benchmark; that is, set the policy parameter to a carbon cap ratio. Let the carbon cap ratio be $C_{\text {cap }}$, and set 51 different $C_{\text {cap }}$ values, which are evenly generated from 0.5 to 1 using the LINSPACE function of MATLAB. At each $C_{\text {cap }}$, we analyze all 1,000 problem instances and, respectively, recorded their average values in terms of optimal sustainability level, carbon emission, and profit. The independent variable is $C_{\text {cap }}$, whereas the dependent variables are sustainability level, profit, and carbon emission. Three regression models are constructed as shown in equations (14)-(16), and the regression results are shown in Table 4:

$$
\begin{aligned}
& S_{1}=\alpha_{11}+\beta_{11} C_{\text {cap }}+\varepsilon . \\
& E_{1}=\alpha_{12}+\beta_{12} C_{\text {cap }}+\varepsilon . \\
& Z_{1}=\alpha_{13}+\beta_{13} C_{\text {cap }}+\varepsilon .
\end{aligned}
$$

The regression results show that the sustainability level negatively correlates with the carbon cap ratio, whereas 
carbon emission and profit positively correlate with the carbon cap ratio. The smaller the carbon cap ratio, the smaller the carbon cap. To meet the carbon cap requirements, enterprises must further increase the sustainability level. Increasing the sustainability level reduces carbon emission, whereas increasing the cost of sustainable investment reduces the profits. The simulation results show that when the carbon cap ratio increases by $1 \%$, the sustainability level decreases by 0.01672 , the carbon emission increases by $1,318.623 \mathrm{~kg}$, and the profit increases by $\$ 200.797$.

5.2. Effects of Carbon Tax Price under Carbon Tax Regulation. To analyze the effects of carbon tax price, we set 101 different $C_{T}$ values that are evenly generated from 0 to 1 using LINSPACE function of MATLAB. At each $C_{T}$, we analyze all 1,000 problem instances and, respectively, recorded their average values in terms of optimal sustainability level, carbon emission, and profit. Regression analyses are carried out to analyze the effects of carbon tax price $C_{T}$ on sustainability level, profit, and carbon emission. By using the data generated from simulation results under carbon tax regulation, we developed three regression models as shown in equations (17)-(19). Then, we present the regression results in Table 5:

$$
\begin{aligned}
& S_{2}=\alpha_{21}+\beta_{21} C_{T}+\varepsilon . \\
& E_{2}=\alpha_{22}+\beta_{22} C_{T}+\varepsilon . \\
& Z_{2}=\alpha_{23}+\beta_{23} C_{T}+\varepsilon .
\end{aligned}
$$

The regression results show that the sustainability level significantly positively correlates with carbon tax price, whereas carbon emission and profit significantly negatively correlate with carbon tax price. When carbon tax price increases by $\$ 1 /$ ton, the sustainability level will increase by 0.000714 , but carbon emission and profit will decrease by $69.228 \mathrm{~kg}$ and $\$ 121.570$, respectively. As the carbon tax raises the sustainability level, the cost of sustainable investment also increases. Although the increase in carbon tax prices can reduce carbon emission, it does not necessarily reduce the amount of carbon taxes. The economic income brought by the sustainability level cannot offset the increase of sustainable investment cost and carbon tax amount, causing the profit to decline.

5.3. Effects of Carbon Cap and Trading Price under Carbon Cap-and-Trade Regulation. Under the carbon cap-andtrade policy, we set carbon cap ratio to $C_{\text {cap }} \sim U[0.5,1]$ (i.e., the same as the carbon cap policy) and carbon trading price to $C_{p} \sim U[0,1]$. The carbon cap ratio and the carbon trading price randomly generate 1,001 random policy combinations in MATLAB. These 1,001 different policies are applied to 1,000 different situations, and the operations under different policies are simulated. By performing regression analysis on the simulation results, the regression model is obtained, as shown in equations (20)-(22). Moreover, the regression results are shown in Table 6:

$$
\begin{aligned}
& S_{3}=\alpha_{31}+\beta_{31} C_{p}+\varepsilon . \\
& E_{3}=\alpha_{32}+\beta_{32} C_{p}+\varepsilon . \\
& Z_{3}=\alpha_{33}+\beta_{33} C_{p}+\beta_{34}\left(C_{p} * C_{\text {cap }}\right)+\varepsilon .
\end{aligned}
$$

The results show that $\beta_{31}>0$, which indicates that the sustainability level is positively related to the carbon trading price. Meanwhile, the coefficient $\beta_{32}<0$ indicates that carbon emission is inversely related to carbon trading price. Model (22) indicates that the relationship between profit and carbon trading price is affected by the carbon cap ratio; in particular, it has a positive regulatory effect on the relationship between carbon trading prices and profits. When $C_{\text {cap }}$ is greater (less) than 0.616 , carbon trading price positively (negatively) correlates with profit. When $C_{\text {cap }}=1$ and carbon trading price increases $\$ 1 /$ tonne, the profit would increase by $\$ 76.762$. By contrast, when $\mathrm{C}_{\text {cap }}=0.5$ and carbon trading price increases by $\$ 1 /$ tonne, profits would decrease by $\$ 23.078$. When $\mathrm{C}_{\text {cap }}=0.616$, the carbon trading price had no effect on profit. At this critical point, the carbon trading volume is 0 , so no matter what the carbon trading price is, the carbon trading value (turnover) is still 0 . Therefore, the carbon trading price will not have an impact on profit.

Models (20) and (21) indicate that no matter what the carbon price is, when carbon trading price increases by $\$ 1 /$ tonne, the sustainability level will increase by 0.000715 , whereas carbon emission will decrease by $69.466 \mathrm{~kg}$. Comparing the results under the carbon tax, we find that carbon trading price has a similar impact on the sustainability level and carbon emission as carbon tax price. When $C_{\text {cap }}=0$, carbon trading price positively correlates with profit. At this point, when the carbon trading price increases by $\$ 1 /$ tonne, the profit decreases by $\$ 122.920$. Considering the error caused by random factors in simulation, the carbon trading price and the carbon tax price also have the same effect on profit when $C_{\text {cap }}=0$,. The above analysis results show that, under carbon cap-and-trade policy, carbon trading price plays a decisive role in sustainability level and carbon emission, which are dependent on carbon trading price and irrelevant to the carbon cap ratio. However, the carbon cap ratio will affect the enterprises' profit. The larger the carbon cap ratio, the more carbon emission enterprises can emit freely, which should be more beneficial to them. Therefore, when the carbon cap is 0 , the effect of carbon trading policy is similar to that of the carbon tax policy [20]. Therefore, enterprises would choose to operate under the cap-and-trade policy involving incentives rather than under the carbon tax policy involving penalties when the carbon trading price is equal to the carbon tax price $[3,19]$.

\section{Parameters Estimation of Carbon Policies and Discussion}

The above results provide the exemplification of the effects of different carbon emission regulations on the performance of supply chain. In general, carbon policies have 
TABLE 4: Regression results under carbon cap regulation.

\begin{tabular}{lccc}
\hline Variables & Model $(14)$ & Model $(15)$ & Model $(16)$ \\
& $S$ & $E(\mathrm{~kg})$ & $Z_{1}(\$)$ \\
\hline$C_{\mathrm{CAP}}($ standard error) & $-1.672^{* * *}(0.031)$ & $131862.277^{* * *}(2044.752)$ & $20079.715^{* * *}(1130.034)$ \\
Constant (standard error) $>$ & $1.802^{* * *}(0.021)$ & $49569.496^{* * *}(1562.821)$ & $46572.010^{* * *}(863.694)$ \\
Observations & 51 & 51 & 51 \\
$R$-squared & 0.987 & 0.988 & 0.866 \\
\hline
\end{tabular}

${ }^{* * *} p<0.01 ;{ }^{* *} p<0.05 ;{ }^{*} p<0.1$.

TABLE 5: Regression results under carbon tax regulation.

\begin{tabular}{lccc}
\hline Variables & Model $(17)$ & Model $(18)$ & Model $(19)$ \\
& $S(\mathrm{~kg})$ & $Z_{2}(\$)$ & $-121570^{* * *}(906.902)$ \\
\hline$C_{T}(\$ / \mathrm{kg})$ (standard error) & $0.714^{* * *}(0.020)$ & $-69228^{* * *}(2717.332)$ & $56842^{* * *}(524.904)$ \\
Constant (standard error) & $0.312^{* * *}(0.102)$ & $160212^{* * *}(1572.769)$ & 101 \\
Observations & 101 & 101 & 0.994 \\
$R$-squared & 0.927 & 0.868 & \\
$* * * * p<0.01 ; * *<<0.05 * *<0$ & &
\end{tabular}

TABLE 6: Regression results under carbon cap-and-trade regulation.

\begin{tabular}{lccc}
\hline Variables & Model $(20)$ & Model $(21)$ & Model $(22)$ \\
$Z_{3}(\$)$ & $E(\mathrm{~kg})$ & $-122920.356^{* * *}(620.912)$ \\
\hline$C_{p}$ (standard error) & $S$ & $-69466.637^{* * *}(845.203)$ & $199682.801^{* * *}(788.726)$ \\
$C_{p}{ }^{*} C_{\text {cap }}$ (standard error) & $0.715^{* * *}(0.006)$ & & $58381.626^{* * *}(163.311)$ \\
Constant (standard error) & & $160858.469^{* * *}(493.1061)$ & 1001 \\
Observations & $0.324^{* * *}(0.004)$ & 1001 & 0.986 \\
R-squared & 1001 & 0.871 & \\
\hline
\end{tabular}

${ }^{* * *} p<0.01 ;{ }^{* *} p<0.05 ;{ }^{*} p<0.1$.

positive effects on the environment and negative effects on the economy [19]. For the government, the permissive policy cannot achieve improvement of the environment, whereas the severe policy will affect the economic development. It is necessary to design appropriate carbon policy parameters from the perspective of maximizing social welfare.

Social welfare includes economic and environmental utilities. Economic utility is a positive utility. In the research environment of this paper, the economic utility under carbon cap and cap-and-trade policies is the profit of the enterprise, and that under a carbon tax policy includes the carbon tax revenue obtained by the government. Environmental utility is a negative utility, which reflects the environmental damage caused by carbon emission. We use a quadratic environmental damage function to represent environmental utility [46]. The social welfare function is expressed in equation (23). The first and second items in equation (23) are the economic and environmental utilities, respectively:

$$
\mathrm{SW}=U_{\mathrm{ec}}-U_{\mathrm{en}} .
$$

Under the carbon cap policy, $U_{\mathrm{ec}}=\alpha_{13}+\beta_{13} C_{\mathrm{CAP}}$ and $E_{1}=\alpha_{12}+\beta_{12} C_{\mathrm{CAP}}$. Substituting $U_{\mathrm{ec}}$ and $U_{\text {en }}$ into equation (23), we obtain the social welfare as shown in equation (24):

$$
\mathrm{SW}=\alpha_{13}+\beta_{13} C_{\text {cap }}-\frac{\varepsilon\left(\alpha_{12}+\beta_{12} C_{\text {cap }}\right)^{2}}{2} .
$$

By the first-order derivative, the optimal carbon cap ratio that maximizes social welfare under the carbon cap policy can be obtained (equation (24)):

$$
C_{\text {cap }}^{*}=\frac{\beta_{13}-\varepsilon \beta_{12} \alpha_{12}}{\varepsilon \beta_{12}^{2}} .
$$

Set $\varepsilon=10^{-6}$. Substituting the results of the regression models (14)-(16) into equation (25), we obtain the optimal carbon cap ratio $C_{\text {cap }}^{*}=77.8 \%$. The corresponding social welfare, profits, carbon emission, and sustainability levels are shown in Table 7.

Under the carbon tax policy, $E_{2}=\alpha_{22}+\beta_{22} C_{T}$ and $U_{\text {ec }}=\alpha_{23}+\beta_{23} C_{T}+C_{T} E_{2}$, where $C_{T} E_{2}$ is the carbon tax levied by governments. Equation (26) presents the social welfare under the carbon tax policy:

$$
\mathrm{SW}=\alpha_{23}+\beta_{23} C_{T}+C_{T} * E_{2}-\frac{\varepsilon\left(\alpha_{22}+\beta_{22} C_{T}\right)^{2}}{2}
$$

Similarly, through the first-order derivative, the optimal carbon tax price that maximizes social welfare under the carbon tax policy can be obtained from the following equation: 
TABle 7: Decision results under different carbon policies.

\begin{tabular}{|c|c|c|c|c|c|}
\hline Policy level & Parameter value & Social welfare & Profit (\$) & Carbon emission (kg) & Sustainability \\
\hline CAP & $77.8 \%$ & 50618 & 62194 & 152158 & 0.501 \\
\hline TAX & $347 \$ /$ tonne & 52641 & 14657 & 136190 & 0.560 \\
\hline Cap-and-trade & $347 \$ /$ tonne, $77.8 \%$ & 62308 & 69635 & 121054 & 0.573 \\
\hline
\end{tabular}

$$
C_{T}^{*}=\frac{\beta_{23}+\alpha_{22}-\varepsilon \beta_{22} \alpha_{22}}{\varepsilon \beta_{22}^{2}-2 \beta_{22}} .
$$

Based on the results of the regression models (17)-(19), we obtain the optimal carbon tax price $C_{T}^{*}=\$ 347 /$ tonne. The corresponding social welfare, profit, carbon emission, and sustainability level are shown in Table 7.

Under the carbon cap-and-trade policy, $U_{\mathrm{ec}}=\alpha_{33}+$ $\beta_{33} C_{p}+\beta_{34}\left(C_{p} C_{\text {cap }}\right)$ and $E_{3}=\alpha_{32}+\beta_{32} C_{p}$. The social welfare under the carbon cap-and-trade policy is shown in the following equation:

$$
\mathrm{SW}=\alpha_{33}+\beta_{33} C_{p}+\beta_{34}\left(C_{p} C_{\text {cap }}\right)-\frac{\varepsilon\left(\alpha_{32}+\beta_{32} C_{p}\right)^{2}}{2} \text {. }
$$

There are two parameters, that is, $C_{P}$ and $C_{\text {cap }}$, under carbon cap-and-trade policy. Since carbon trading price $C_{P}$ is usually determined by the supply and demand of the carbon trading market, the government mainly needs to decide the $C_{\text {cap }}$ value. Taking the first derivative of SW with respect to $C_{\text {cap }}$, we obtain $\left(\mathrm{dSW} / \mathrm{d} C_{\text {cap }}\right)=\beta_{34} C_{p}>0$. That is, social welfare increases monotonously with the carbon cap ratio. From this, a very interesting conclusion can be drawn: when the carbon cap ratio is $100 \%$, that is, the maximum value, social welfare is maximized. This conclusion indicates that to maximize social welfare, the government should increase the carbon cap as much as possible because it has no restrictive effect on enterprises. Based on the conclusion of the previous regression models, we summarized the causal influence mechanism in the social welfare system under the carbon trading policy in Figure 2.

As shown in the figure, sustainability level and carbon emission are determined by carbon trading price and are not related to carbon cap. The carbon cap will only affect the profit [17]. Therefore, when the carbon trading price is fixed, regardless of the carbon cap, the sustainability level and carbon emission are also fixed, resulting in a fixed environmental utility. The greater the carbon cap, the greater the carbon emission that an enterprise can obtain for free. Moreover, the profit of the enterprise is higher, and the economic utility is greater, and, therefore, the social welfare is greater. To be precise, the maximum social welfare mentioned here actually refers to the social welfare caused by a single enterprise. From the perspective of the whole society, social welfare is actually unchanged. When conducting carbon trading, some companies increase their profits due to the sale of carbon emission rights, and, thus, there must be a decline in profits due to the purchase of carbon emission rights. Therefore, from the perspective of the entire society, carbon trading itself has no impact on economic utility and

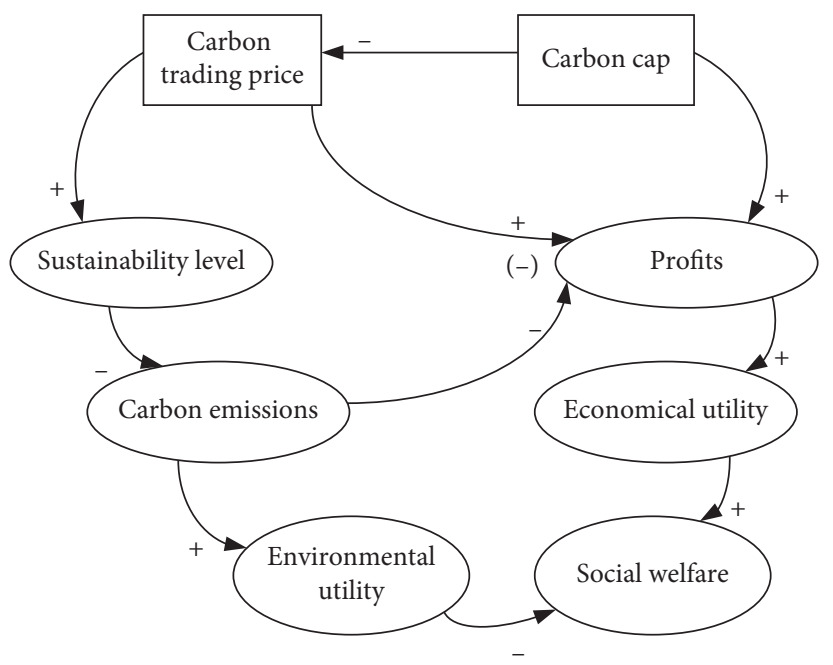

Figure 2: Causal relationships under cap-and-trade policy.

social welfare. Under the carbon cap-and-trade policy, social welfare is determined by the carbon trading price. The government can exert two aspects of regulation effect through a reasonable carbon cap. The first aspect is to adjust the relative balance of profits in different industries through carbon cap. For industries with higher profit margins, a strict carbon cap policy can be adopted. By contrast, industries with lower margins can adopt a loose carbon cap policy. The second aspect is to stabilize the carbon trading price through the carbon cap. When the carbon trading price is high, the carbon cap could be set at a large value to reduce the carbon trading price and vice versa.

To compare the results under various policies, we use the optimal parameter values under the carbon cap and the carbon tax policies. Moreover, the decision results under the carbon cap-and-trade policy are calculated (i.e., $\left(C_{p}=\$ 347 /\right.$ tonne, $\left.\left.C_{\text {cap }}=77.8 \%\right)\right)$. The corresponding social welfare, profit, carbon emission, and sustainability level are shown in Table 7.

The operation results reveal that the sustainability level under the carbon cap policy is the lowest, whereas that under the carbon cap-and-trade policy is the highest. Under the carbon cap policy, the sustainability level is 0.501 , and its carbon emission is the largest of the three policies. The enterprises' emission reduction goal is to control carbon emission within the carbon cap. Hence, when the carbon cap is high, the enterprises' enthusiasm for reducing emissions is not strong. Meanwhile, under the carbon tax policy, social welfare is slightly higher than the carbon cap policy. However, the enterprise's profit is only $\$ 14,657$, and the carbon tax revenue is $\$ 47,258$. This is because under the carbon tax policy, the government is both the leader and the 
beneficiary of the policy, so it sets a relatively high carbon tax price. A high tax price not only can encourage enterprises to increase their sustainability level, reduce carbon tax costs, and improve the economic utility, but also can maintain social welfare at a high level. However, due to high carbon tax price, the enterprise's profit has been greatly reduced. The results shown in Table 7 indicate that the enterprise's profit under the carbon tax policy has fallen by $76.4 \%$ compared with that under the carbon cap policy. Therefore, excessively high carbon tax price will frustrate the enterprise's enthusiasm for sustainable investment [30]. If the enterprise gives up its business because of low profits, it will be a double defeat for the government and the enterprise. Therefore, if the government takes part of the carbon tax revenue to subsidize the enterprise [30], the enterprise's profit will increase, as well as their enthusiasm to achieve a win-win situation. The social welfare, enterprise's profit, and carbon emission under the carbon cap-and-trade policy are superior to those under the carbon cap policy and carbon tax policy [42]. This is because carbon cap-and-trade policy absorbs the advantages of carbon cap and carbon tax policies. To obtain greater profit, enterprises have increased their sustainability levels to reduce their carbon emission. They could even make greater profits by selling the remaining carbon emission rights. The analysis results show that a single carbon policy has certain limitations, and a composite carbon policy can consider both the economic and emission reduction goals, thereby achieving the coordination of economic and environmental utilities.

\section{Conclusions}

Integrating environmental factors into inventory-transportation problem is a hot topic in sustainable development, and carbon policies such as cap, tax, and cap-and-trade are regarded as effective ways to reduce carbon emission. However, research on the integrated inventory-transportation model simultaneously taking into account consumer environmental consciousness, sustainable investment, and carbon policies on a global scale is lacking. Under carbon cap, tax, and cap-and-trade policies, we investigated consumer environmental consciousness extended in inventory-transportation problem with demand dependent on the sustainability level of the product. First, we examined four integrated inventory-transportation models under different policy cases (i.e., no carbon policy, cap, tax, and cap-and-trade) and presented corresponding algorithms to optimize EOQ by giving sustainability level. Second, we designed a simulation method to determine the appropriate sustainability level and EOQ simultaneously. Third, we performed simulations under carbon cap, tax, and cap-andtrade policies, and we used regression models to analyze the effect of carbon policies on the sustainability level, profit, and carbon emission. Finally, by maximizing social welfare, we estimated and discussed carbon policy parameters on the basis of the regression results.

Under carbon cap policy, the carbon cap positively correlates with enterprises' profit and carbon emission but negatively correlates with the sustainability level.
Meanwhile, under carbon tax policy, the carbon tax price significantly positively correlates with the sustainability level but negatively correlates with enterprises' profit and carbon emission. Moreover, under carbon cap-and-trade policy, the carbon trading price is the decisive factor that affects the sustainability level, enterprises' profit, and carbon emission. The carbon cap has no effect on the sustainability level and enterprises' carbon emission but has a positive regulatory effect on the relationship between carbon trading prices and profits. Furthermore, the carbon trading price is positively related to the sustainability level and inversely related to carbon emission. When carbon trading price is low (high), carbon trading price negatively (positively) correlates with profit. The results indicate that carbon cap-and-trade policy is superior to carbon cap and tax policies because it could absorb the advantages of the single carbon policy and achieve the coordination of economic and environmental utilities.

Under carbon cap and tax policies, policy parameters could be estimated from the perspective of social welfare maximization by using regression models. The governments tend to set a high carbon tax parameter because they benefit from the carbon tax. However, a high carbon tax parameter will markedly decrease enterprises' profit, which has a significantly negative effect on enterprises' enthusiasm for sustainable investment. Therefore, the government subsidy strategy is needed when a severe carbon tax policy is adopted. Under the carbon cap-and-trade policy, the carbon trading price has the same effect as the carbon tax price when the carbon cap is 0 . The situation when carbon cap is 0 means that enterprises do not have free carbon emission permits. At this point, the same drawback as carbon tax policy will occur; that is, enterprises' profit will be decreased markedly. Hence, the governments should avoid the situation to promote the initiative of enterprises to reduce emissions in practice. Though governments cannot estimate carbon cap parameter by maximizing social welfare, they should set an appropriate carbon cap parameter according to the profit of enterprise and carbon trading price to play its regulatory role.

The novel contributions of this paper are as follows. Integrated inventory-transportation optimization models considering the sustainability of the product under carbon cap, tax, cap-and-trade policies were developed. To our knowledge, this is the first study to combine consumer environmental awareness, sustainable technology, and comprehensive emission model in inventory-transportation problem, thereby closing this gap in the literature. Furthermore, simulations were designed to optimize inventorytransportation models. Based on the simulation results, regression models are proposed to analyze the effect of carbon policy parameters on sustainability level, profit, and emission. The policy parameters are estimated and analyzed using the regression results. The proposed models could be used as a reference for enterprises needing to formulate inventory-transportation scheduling and governments intending to implement carbon policies.

Although this paper has several novel contributions, certain limitations should be considered. Future research 
should address the following aspects: (1) The homogeneous vehicle was used as a delivery medium in the model. The possible extension of the model is to consider heterogeneous vehicles in future studies. (2) Our research assumes a single item. Extending the model with multiple items is also a direction worthy of further study. (3) We assume that the carbon label only includes carbon emission in production. In the future research, the carbon emission in inventory and transportation should be included in the carbon label, thereby making the optimization model more complicated and challenging. (4) The last extension worth mentioning is to expand inventory-transportation model using more complex logistics networks, such as "one-to-many" or "many-to-many", and consider varying consumer environmental consciousness in different markets.

\section{Data Availability}

The data used to support the findings of this study are available from the corresponding author upon request.

\section{Conflicts of Interest}

The authors declare that they have no conflicts of interest.

\section{Acknowledgments}

This research was funded by the research project on $\mathrm{Hu}-$ manity and Social Science of the Ministry of Education in China (Grant no. 17YJAZH074) and the Key Subject Development Project of Management Science and Engineering of Hubei University of Education.

\section{References}

[1] C. Xu, X. Liu, C. Wu, and B. Yuan, "Optimal inventory control strategies for deteriorating items with a general time-varying demand under carbon emission regulations," Energies, vol. 13, no. 4, p. 999, 2020.

[2] H. Yang and W. Chen, "Retailer-driven carbon emission abatement with consumer environmental awareness and carbon tax: revenue-sharing versus cost-sharing," Omega, vol. 78, pp. 179-191, 2018.

[3] Y.-S. Huang, C.-C. Fang, and Y.-A. Lin, "Inventory management in supply chains with consideration of Logistics, green investment and different carbon emissions policies," Computers \& Industrial Engineering, vol. 139, p. 106207, 2020.

[4] Y.-J. Zhang, A.-D. Wang, and W. Tan, "The impact of China's carbon allowance allocation rules on the product prices and emission reduction behaviors of ETS-covered enterprises," Energy Policy, vol. 86, pp. 176-185, 2015.

[5] D. Konur and B. Schaefer, "Integrated inventory control and transportation decisions under carbon emissions regulations: LTL vs. TL carriers," Transportation Research Part E: Logistics and Transportation Review, vol. 68, pp. 14-38, 2014.

[6] U. Mishra, J.-Z. Wu, and B. Sarkar, "A sustainable production-inventory model for a controllable carbon emissions rate under shortages," Journal of Cleaner Production, vol. 256, p. 120268, 2020.

[7] E. Koberg and A. Longoni, "A systematic review of sustainable supply chain management in global supply chains," Journal of Cleaner Production, vol. 207, pp. 1084-1098, 2019.
[8] Y. Cheng, H. Sun, F. Jia, and L. Koh, "Pricing and low-carbon investment decisions in an emission dependent supply chain under a carbon labelling scheme," Sustainability, vol. 10, no. 4, p. 1238, 2018.

[9] S. Du, J. Zhu, H. Jiao, and W. Ye, "Game-theoretical analysis for supply chain with consumer preference to low carbon," International Journal of Production Research, vol. 53, no. 12, pp. 3753-3768, 2015.

[10] Y. Cheng, Y. Kuang, X. Shi, and C. Dong, "Sustainable investment in a supply chain in the big data era: an information updating approach," Sustainability, vol. 10, no. 2, p. 403, 2018.

[11] I. Nouira, Y. Frein, and A. B. Hadj-Alouane, "Optimization of manufacturing systems under environmental considerations for a greenness-dependent demand," International Journal of Production Economics, vol. 150, pp. 188-198, 2014.

[12] S. A. R. Khan, Y. Zhang, M. Anees, H. Golpîra, A. Lahmar, and D. Qianli, "Green supply chain management, economic growth and environment: a GMM based evidence," Journal of Cleaner Production, vol. 185, pp. 588-599, 2018.

[13] C. Dong, B. Shen, P.-S. Chow, L. Yang, and C. T. Ng, "Sustainability investment under cap-and-trade regulation," Annals of Operations Research, vol. 240, no. 2, pp. 509-531, 2016.

[14] P. Rao and D. Holt, "Do green supply chains lead to competitiveness and economic performance?" International Journal of Operations \& Production Management, vol. 25, no. 9, pp. 898-916, 2005.

[15] O. Jabali, T. Van Woensel, and A. G. de Kok, "Analysis of travel times and CO2Emissions in time-dependent vehicle routing," Production and Operations Management, vol. 21, no. 6, pp. 1060-1074, 2012.

[16] Y. Bouchery, A. Ghaffari, Z. Jemai, and T. Tan, "Impact of coordination on costs and carbon emissions for a two-echelon serial economic order quantity problem," European Journal of Operational Research, vol. 260, no. 2, pp. 520-533, 2017.

[17] S. Tang, W. Wang, S. Cho, and H. Yan, "Reducing emissions in transportation and inventory management: (R, Q) Policy with considerations of carbon reduction," European Journal of Operational Research, vol. 269, no. 1, pp. 327-340, 2018.

[18] S. Benjaafar, Y. Li, and M. Daskin, "Carbon footprint and the management of supply chains: insights from simple models," IEEE Transactions on Automation Science and Engineering, vol. 10, pp. 99-116, 2013.

[19] A. Toptal, H. Özlü, and D. Konur, "Joint decisions on inventory replenishment and emission reduction investment under different emission regulations," International Journal of Production Research, vol. 52, no. 1, pp. 243-269, 2014.

[20] G. J. L. Micheli and F. Mantella, "Modelling an environmentally-extended inventory routing problem with demand uncertainty and a heterogeneous fleet under carbon control policies," International Journal of Production Economics, vol. 204, pp. 316-327, 2018.

[21] A. Mosca, N. Vidyarthi, and A. Satir, "Integrated transportation - inventory models: a review," Operations Research Perspectives, vol. 6, p. 100101, 2019.

[22] A. Toptal, S. Çetinkaya, and C.-Y. Lee, "The buyer-vendor coordination problem: modeling inbound and outbound cargo capacity and costs," Iie Transactions, vol. 35, no. 11, pp. 987-1002, 2003.

[23] M. Soysal, J. M. Bloemhof-Ruwaard, R. Haijema, and J. G. A. J. van der Vorst, "Modeling a green inventory routing problem for perishable products with horizontal collaboration," Computers \& Operations Research, vol. 89, pp. 168-182, 2018. 
[24] S. Bose, A. Goswami, and K. S. Chaudhuri, "An EOQ model for deteriorating items with linear time-dependent demand rate and shortages under inflation and time discounting," The Journal of the Operational Research Society, vol. 46, no. 6, pp. 771-782, 1995.

[25] R. R. Chowdhury, S. Ghosh, and K. Chaudhuri, “An optimal inventory replenishment policy for a perishable item with time quadratic demand and partial backlogging with shortages in all cycles," International Journal of Applied and Computational Mathematics, vol. 3, pp. 1001-1017, 2017.

[26] L. Bertazzi, A. Bosco, and D. Laganà, "Managing stochastic demand in an Inventory Routing Problem with transportation procurement," Omega, vol. 56, pp. 112-121, 2015.

[27] S. Sindhuchao, H. E. Romeijn, E. Akçali, and R. Boondiskulchok, "An integrated inventory-routing system for multi-item joint replenishment with limited vehicle capacity," Journal of Global Optimization, vol. 32, no. 1, pp. 93-118, 2005.

[28] V. Hovelaque and L. Bironneau, "The carbon-constrained EOQ model with carbon emission dependent demand," International Journal of Production Economics, vol. 164, pp. 285-291, 2015.

[29] B. Rabta, "An Economic Order Quantity inventory model for a product with a circular economy indicator," Computers \& Industrial Engineering, vol. 140, Article ID 106215, 2020.

[30] S. Wang, F. Tao, and Y. Shi, "Optimization of inventory routing problem in refined oil logistics with the perspective of carbon tax," Energies, vol. 11, no. 6, p. 1437, 2018.

[31] D. Zhang, Q. Zhan, Y. Chen, and S. Li, "Joint optimization of logistics infrastructure investments and subsidies in a regional logistics network with CO2 emission reduction targets," Transportation Research Part D: Transport and Environment, vol. 60, pp. 174-190, 2018.

[32] Z. Rafie-Majd, S. H. R. Pasandideh, and B. Naderi, "Modelling and solving the integrated inventory-location-routing problem in a multi-period and multi-perishable product supply chain with uncertainty: Lagrangian relaxation algorithm," Computers \& Chemical Engineering, vol. 109, pp. 9-22, 2018.

[33] M. Alım and P. Beullens, "Joint inventory and distribution strategy for online sales with a flexible delivery option," International Journal of Production Economics, vol. 222, Article ID 107487, 2020.

[34] P. Gautam, A. Kishore, A. Khanna, and C. K. Jaggi, "Strategic defect management for a sustainable green supply chain," Journal of Cleaner Production, vol. 233, pp. 226-241, 2019.

[35] M. Biuki, A. Kazemi, and A. Alinezhad, "An integrated location-routing-inventory model for sustainable design of a perishable products supply chain network," Journal of Cleaner Production, vol. 260, Article ID 120842, 2020.

[36] J. Xu, X. Cui, Y. Chen, and X. Zhang, “Joint transportation and inventory strategy for perishable items with weibull distribution under carbon emission regulations," Mathematical Problems in Engineering, vol. 2018, Article ID 7589647, 11 pages, 2018.

[37] G. Hua, T. C. E. Cheng, and S. Wang, "Managing carbon footprints in inventory management," International Journal of Production Economics, vol. 132, no. 2, pp. 178-185, 2011.

[38] X. Chen, S. Benjaafar, and A. Elomri, "The carbon-constrained EOQ," Operations Research Letters, vol. 41, no. 2, pp. 172-179, 2013.

[39] H. Liao and Q. Deng, "A carbon-constrained EOQ model with uncertain demand for remanufactured products," Journal of Cleaner Production, vol. 199, pp. 334-347, 2018.
[40] Y. Yu, X. Han, and G. Hu, "Optimal production for manufacturers considering consumer environmental awareness and green subsidies," International Journal of Production Economics, vol. 182, pp. 397-408, 2016.

[41] L. Zhang, J. Wang, and J. You, "Consumer environmental awareness and channel coordination with two substitutable products," European Journal of Operational Research, vol. 241, no. 1, pp. 63-73, 2015.

[42] D. F. Drake, P. R. Kleindorfer, and L. N. Van Wassenhove, "Technology choice and capacity portfolios under emissions regulation," Production and Operations Management, vol. 25, no. 6, pp. 1006-1025, 2016.

[43] Z. Tao and J. Xu, "Carbon-regulated EOQ models with consumers' low-carbon awareness," Sustainability, vol. 11, no. 4, p. 1004, 2019.

[44] C. Su, X. Liu, and W. Du, "Green supply chain decisions considering consumers' low-carbon awareness under different government subsidies," Sustainability, vol. 12, no. 6, p. 2281, 2020.

[45] H. L. Lee and M. J. Rosenblatt, "A generalized quantity discount pricing model to increase supplier's profits," Management Science, vol. 32, no. 9, pp. 1177-1185, 1986.

[46] T. A. Weber and K. Neuhoff, "Carbon markets and technological innovation," Journal of Environmental Economics and Management, vol. 60, no. 2, pp. 115-132, 2010. 